NASA-CR-205299

\title{
Diagenetic layers in the upper walls of Valles Marineris, Mars: Evidence for drastic climate change since the mid- Hesperian
}

\author{
Allan H. Treiman \\ Lunar and Planetary Institute, Houston, Texas \\ Kelly H. Fuks 1 \\ Department of Geology, Georgia State University, Atlanta \\ Scott Murchie \\ Applied Physics Laboratory, Laurel, Maryland
}

\begin{abstract}
A packet of relatively resistant layers, totaling $\sim 400 \mathrm{~m}$ thickness, is present at the tops of the chasma walls throughout Valles Marineris. The packet consists of an upper dark layer ( $\sim 50 \mathrm{~m}$ thick), a central bright layer ( $250 \mathrm{~m}$ thick), and a lower dark layer ( $\sim 100 \mathrm{~m}$ thick). The packet appears continuous and of nearly constant thickness and depth below ground surface over the whole Valles system $(4000 \mathrm{~km} \mathrm{E}-\mathrm{W}, 800 \mathrm{~km}$ $\mathrm{N}-\mathrm{S}$ ), independent of elevation (3-10 km) and age of plateau surface (Noachian through upper Hesperian). The packet continues undisturbed beneath the boundary between surface units of Noachian and Hesperian ages, and continues undisturbed beneath impact craters transected by chasma walls. These attributes are not consistent with layer formation by volcanic or sedimentary deposition, and are consistent with layer formation in situ, i.e., by diagenesis, during or after upper Hesperian time. Diagenesis seems to require the action of aqueous solutions in the near subsurface, which are not now stable in the Valles Marineris area. To permit the stability of aqueous solutions, Mars must have had a fairly dense atmosphere, $\geq 1$ bar $\mathrm{CO}_{2}$, when the layers formed. Obliquity variations appear to be incapable of producing such a massive atmosphere so late in Mars' history.
\end{abstract}

\section{Introduction}

The uppermost walls of the Valles Marineris exhibit layering, marked by differences in color and material strength, thatcan be followed continuously for tens to hundreds of kilometers [Lucchitta, 1978; Lucchitta et al., 1992]. The layers have been interpreted as expressions of lava flows or other "resurfacing units" [Davis and Golombek, 1990; Lucchitta et al., 1992], although the character and continuity of the layering had not been investigated systematically.

To better understand the origin of the upper wall layering, we mapped its lateral extent and estimated its elevations, thicknesses, and stratigraphies using Viking orbiter and Mariner 9 images and Viking elevation data. Where possible, images with spatial resolution $\leq 60 \mathrm{~m} /$ pixel were used. Viking orbiter (VO) images at this resolution are available for most of the

\footnotetext{
1 Now at Department of Geological Sciences, University of Michigan
}

Copyright 1995 by the American Geophysical Union.

Paper number 95JE03223.

0148-0277/95/95JE-03223\$05.00
Hebes, Ophir, Candor, Melas, and eastern Coprates Chasmata; VO images at $\leq 200 \mathrm{~m} /$ pixel cover the remainder of the Valles Marineris. VO images with resolution to $15 \mathrm{~m} /$ pixel are available and were used for a portion of Tithonium Chasma and a small area in southern Melas Chasma. Most of the images were taken through clear or red filters. Where possible, digital imagery was contrast-enhanced and filtered to emphasize layering; otherwise, photographic prints were used.

For each examined reach of wall, albedo and morphology of the layering were estimated using standard photointerpretative techniques. Thicknesses of layers were estimated from height of the wall exposures [U.S. Geological Survey, 1991, 1993] and the fraction of the walls occupied by the layering. This semiquantitative method assumes that the slope of each wall is effectively constant from top to base, as shown to first order by the photoclinometric profiles of Davis and Golombek [1990]. The thickness, albedo, and morphologic observations were then combined to produce a stratigraphic column for each section. The stratigraphic relations of the layering were investigated by comparing the depth of layering beneath the Martian surface with the depth of the late-Noachian surface predating the Tharsis volcanic sequence (Hesperian age). The latter was mapped by DeHon $[1982,1985,1988]$ using mapped boundaries of geologic units and the size distribution of partially buried craters exposed within each unit. 


\section{Upper Wall Layering}

Layering was observed throughout the Valles Marineris on relatively planar wall faces, i.e., on the heads of landslides (Figures 1 and 2) and on probable fault scarps in Coprates Chasma. The layering is less evident and sometimes not apparent in more irregular walls exhibiting spur-and-gully topography (Figure la), and in imagery with unfavorable lighting or taken through the blue filter. Albedo differences on Mars are generally more subdued in blue-wavelength images than in the red- and clear-filter images that account for most of the data we examined [Soderblom, 1992]. The layering is only rarely visible on images with spatial resolution $>150 \mathrm{~m} /$ pixel, and there only on the most favorably oriented slopes. However, the layering is visible in nearly every clear- or red-filter VO
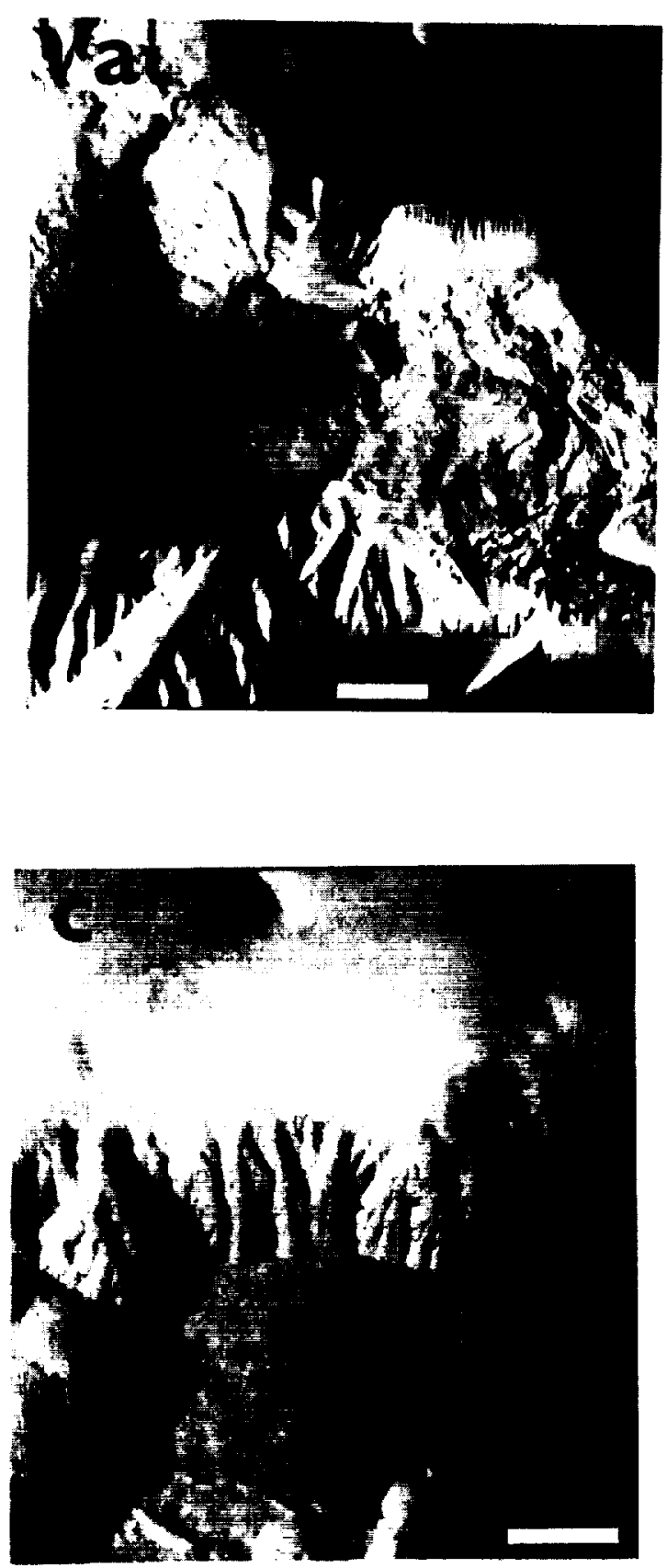

image of adequate spatial resolution that shows planar wall segments of the Valles Marineris (Figure 2).

The type section of upper wall layering is taken at the head scarp of a large landslide at the southeast wall of Hebes Chasma (Figure 1a). The scarp is $-2 \mathrm{~km}$ from plateau rim to base, and has an average slope of $\sim 30^{\circ}$. At the wall top is an upper dark layer, $\sim 50 \mathrm{~m}$ thick, which forms a "cliff." Beneath is a brighter, slope-forming layer, $\sim 250 \mathrm{~m}$ thick, followed by a dark, more resistant layer, $\sim 75 \mathrm{~m}$ thick. The lower portion of the scarp is in bright material without identifiable lithologic boundaries; it may expose only debris slopes and cones. An identical section is exposed on the north wall of Hebes Chasma (Figure la). Stratigraphic sections for this and other exposures in Valles Marineris are given in Figure 3. In some areas, higher resolution imagery permits identification of subsidiary layers within the

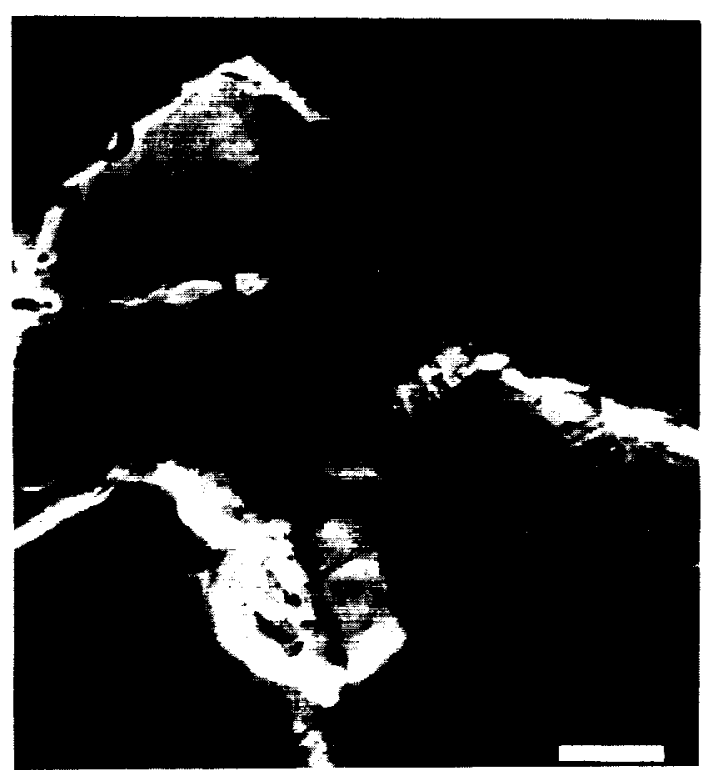

Figure 1. Layering in the upper walls of Valles Marineris. (a) Type exposure: southeast wall of Hebes chasma, layering exposed (arrow) near top of landslide scarp ( $\sim 2 \mathrm{~km}$ tall, $\sim 30^{\circ}$ slope angle). VO $915 \mathrm{~A} 06\left(2.2^{\circ} \mathrm{S}, 73.5^{\circ} \mathrm{W}\right)$, scale bar $10 \mathrm{~km}$, north toward top, illumination from right; site A of Figure 2. Layering is poorly visible in spur-and-gully walls to $\mathrm{W}$ of scarp. (b) Best exposure of layering packet (arrow) in Noctis Labyrinthus (note reseau marks on image). VO $049 \mathrm{~A} 26\left(5.2^{\circ} \mathrm{S}\right.$, $104.7^{\circ} \mathrm{W}$ ), scale bar $10 \mathrm{~km}$, north toward top, illumination from upper right; site B of Figure 2. (c) Eastern south wall of Coprates Chasma, VO $428 \mathrm{~A} 73\left(15.9^{\circ} \mathrm{S}, 52.5^{\circ} \mathrm{W}\right)$, scale bar 10 $\mathrm{km}$; north to top, illumination from right; site C of Figure 2. (d) South wall of Gangis Chasma, VO $014 \mathrm{~A} 30$ (centered $9.7^{\circ} \mathrm{S}$, $44.6^{\circ} \mathrm{W}$ ), oblique view looking south, scale bar $10 \mathrm{~km} \mathrm{E-W} \mathrm{at}$ chasma wall; site D of Figure 2. Uppermost dark unit (left arrow) appears to transgress crater rim and terminate at interior crater wall. Lower dark (right arrow) unit continues undeflected from plains to crater floor under crater rim. An additional layer present on the west (right) side of the crater thickens and deepens beneath it. Continuity and thickening of the layers are also visible on VO $610 \mathrm{~A} 34$. 


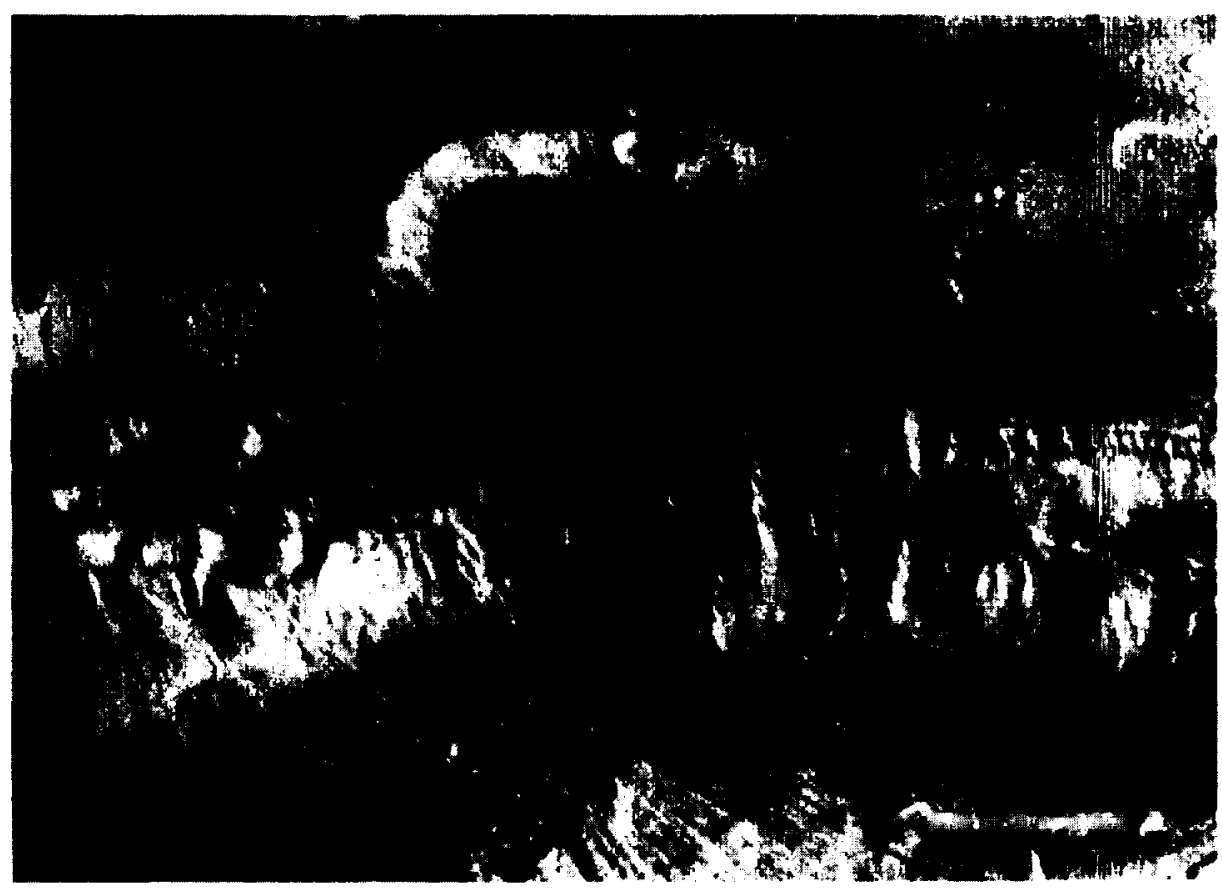

Figure 1. (Continued).

layering packet (e.g., VO 737A63 of Tithonium Chasma, VO $066 \mathrm{~A} 17$ of Ius Chasma); up to eight layers have been reported [Lucchitta et al., 1992].

Packets of layers like the Hebes type section are visible within $\sim 50 \mathrm{~m}$ of the tops of chasma walls throughout the Valles Marineris, as shown in Figure 2, from western Noctis Labyrinthus $\left(110^{\circ} \mathrm{W}\right.$, VO $\left.423 \mathrm{~A} 75\right)$ through eastern Eos Chasma $\left(31^{\circ} \mathrm{W}\right.$, VO $\left.964 \mathrm{~A} 22\right)$. More than $900 \mathrm{VO}$ images were examined to establish the exposures of the layering packet. Figure 2 shows the wall reaches where, on single and overlapping VO images, a layer packet is visible either as a "cliff" at the wall tops or as a "dark-bright-dark" albedo pattern. In Noctis Labyrinthus, most pits and rifts have an undifferentiated "cliff" at their tops. The pit of Figure $1 \mathrm{~b}$, one of the deepest in Noctis Labyrinthus, has the best observed exposure of the layering packet, and clearly shows all three layers. Exposures in the central Valles Marineris are similar to that in Hebes Chasma (Figure la) described above. The thickest layer packet observed is on the wall of southeastern Coprates Chasma (Figure 1c) where the whole packet is $750 \mathrm{~m}$ thick and the lower dark layer

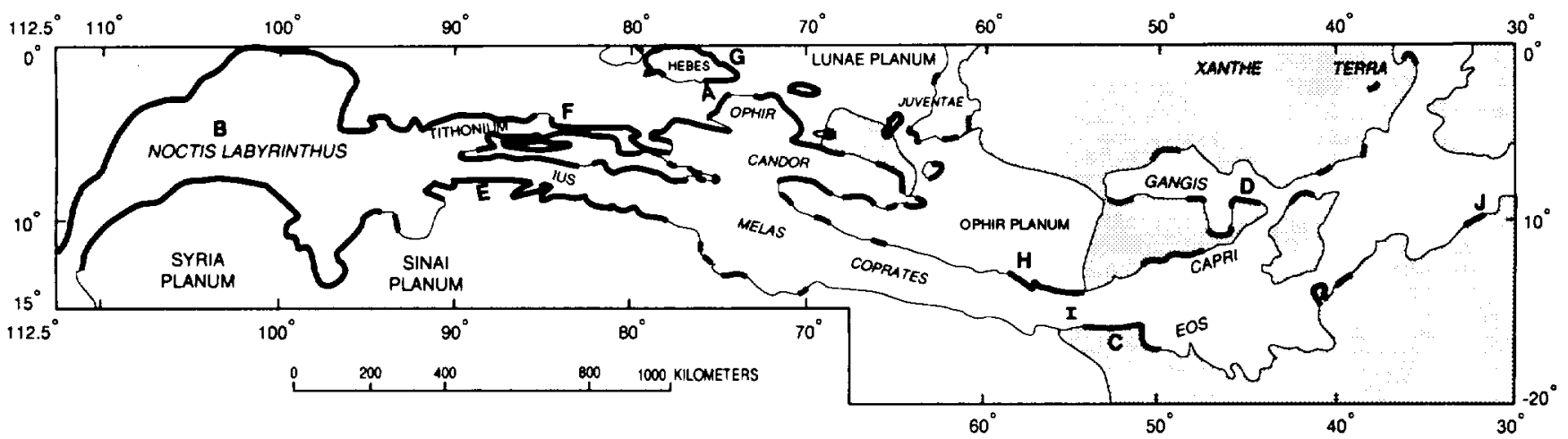

Figure 2. Outline of the walls of Valles Marineris. Heavy line, upper wall layering packet visible; light line, layering not visible. Each solid line reflects single or overlapping images which clearly show the upper wall layering as a cliff of relatively resistant material, as dark-bright-dark albedo layering, or both. Walls without visible layering are mostly either of spur and gully morphology, or were imaged only at resolutions $>150 \mathrm{~m} /$ pixel. Plains and terrae above Valles Marineris are Hesperian age, except in the east, where Noachian-age surfaces are shaded. Letters are locations of images in Figure 1 and stratigraphic sections in Figure 3. The Noctis Labyrinthus province is shown in heavy line, as layering is exposed in the walls of most of its pits and valleys. The limited observed exposures of the upper wall layering in eastern Valles Marineris (Coprates, Gangis, Eos, Capri Chasmae) may merely reflect the paucity of high-resolution $(<100 \mathrm{~m} / \mathrm{pixel})$ imagery of this area. 
is $250 \mathrm{~m}$ thick (Figure 3). Farther east and north the layering packet thins, as shown in south wall of Gangis Chasma (Figures 1d and 3). The Gangis Chasma exposure is also significant because the layering packet can be traced nearly continuously beneath the unnamed crater on the chasma wall.

The layering packet is extraordinarily extensive and consistent throughout Valles Marineris. Nearly identical sequences are exposed in cliff walls over the whole Valles Marineris system, an area of $>4000 \mathrm{~km}$ by $\sim 800 \mathrm{~km}$ (Figure 2). The layering can be traced continuously in overlapping VO frames for $\sim 200-300 \mathrm{~km}$ along walls in Hebes Chasma, along the north wall of Ius Chasma, and from southwestern Eos Chasma along the eastern south wall of Coprates Chasma (Figure 1c). The last exposure may also continue westward an additional $1000 \mathrm{~km}$ to Melas Chasma, based on the best available ( $200 \mathrm{~m} / \mathrm{pixel})$ imagery of the central and western south wall of Coprates Chasma (VO 610A04, 610A08).

The character of the layering is remarkably unaffected by physiographic variations in the overlying plateau surface. Layering thicknesses and structure show no relationship with plateau elevation, which ranges from +1.5 to $+10 \mathrm{~km}$ (Figure 3), or with plateau surface ages, which ranges from Noachian through upper Hesperian (Figures 2 and 3). The upper horizon of the layer packet remains at effectively zero depth, even though the thickness of the post-Noachian Tharsis volcanic sequence varies from zero to $>600 \mathrm{~m}[\mathrm{DeHon}, 1982,1985$, 1988]. The layering also continues nearly without interruption beneath impact craters up to $30 \mathrm{~km}$ in diameter (Figure 1d) in units $\mathrm{Hr}$ and $\mathrm{Npl} 2$ [Witbeck et al., 1991].

\section{Regional Correlations}

Other researchers have commented on layering in the shallow crust in and around the Valles Marineris. The layers we describe have been noted previously, especially by Lucchitta [1978] and Lucchitta et al. [1992]. Davis and Golombek [1990] used photoclinometry to delineate structural discontinuities at 0.3-0.6 $\mathrm{km}, 1 \mathrm{~km}$, and $2-3 \mathrm{~km}$ beneath the plains surrounding Valles Marineris. The first discontinuity may correspond to the base of

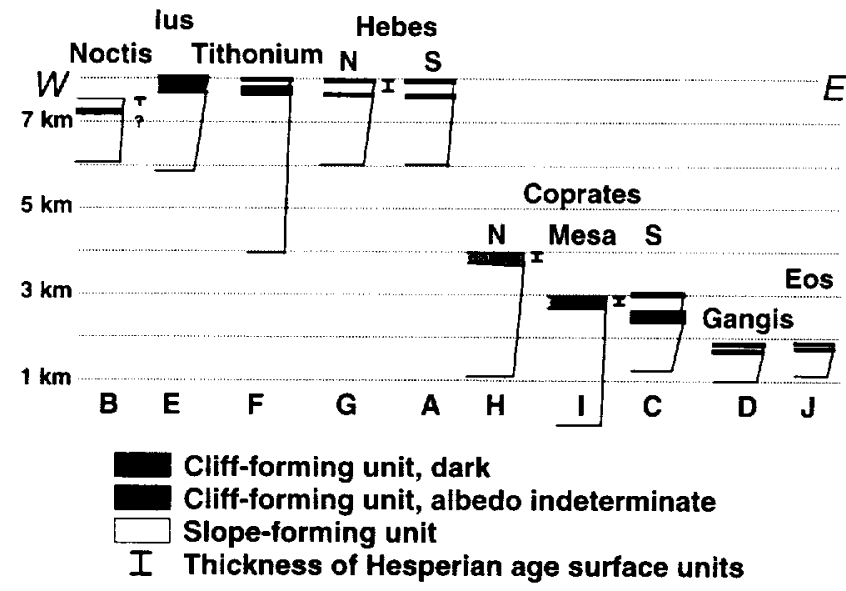

Figure 3. Stratigraphic columns of the Valles Marineris walls, selected locations, arranged from west to east. Locations of stratigraphic columns, shown on Figure 2, are keyed to letters below each column. Elevation (vertical axis) is relative to the datum [U.S.Geological Survey, 1991]. I-beams show inferred thicknesses of Hesperian resurfacing materials, probably volcanic [DeHon, 1982, 1985, 1988]. the layering packet described here; Davis and Golombek suggested that the discontinuity was the base of the Tharsis volcanic sequence. We saw no evidence in the Valles walls for the $1 \mathrm{~km}$ or $2-3 \mathrm{~km}$ discontinuities, which have been ascribed to cementation at an ice-water interface [Soderblom and Wenner, 1978], and to the top of megaregolith [Fanale, 1976] or possibly the base of ice-saturated regolith [Clifford, 1993] respectively. Robinson and Tanaka [1988] reported a 1-km structural discontinuity beneath Lunae Planum north of Valles Marineris, but no evidence for the $0.3-0.6 \mathrm{~km}$ discontinuity. The dark layers described by Geissler et al. [1990] in Coprates, Juventae, and Ophir Chasmae are beneath the layering packet described here. This relationship is best shown in their Figure 5 (VO538A38) of Ophir Chasma, where cliffs at the wall tops are distinctly above exposures of their dark layer.

\section{Interpretations}

The stratigraphy and thicknesses of the layers at the wall tops are nearly uniform throughout the Valles Marineris, which is particularly notable given the exposure area of $>4000 \mathrm{~km}$ by $800 \mathrm{~km}$; the packet of layers is visible on uncovered, ungullied walls in nearly every image where viewing geometry and resolution are adequate (Figure 2), and on some gullied walls observed under favorable illumination. This lateral continuity suggests that the layering packet represents a single geologic feature. We consider two modes for formation of the layering: depositional, volcanic or sedimentary material added onto the land surface; and diagenetic, formation in situ below the land surface by modification of preexisting materials.

A depositional origin, volcanic or sedimentary, for the layering packet seems unlikely because it would be inconsistent with the observed transgression of the marker horizon formed by the base of the Tharsis volcanic sequence (Figure 2). In the eastern part of the chasma system, the plateau surface is Naachian-age cratered, ridged, and smooth plains. To the west, the plateau surface is late Hesperian-aged smooth volcanic plains, which range to $>600 \mathrm{~m}$ in thickness [DeHon, 1982, 1985, 1988]. In both settings, however, the layering packet is nearly constant in both thickness and depth beneath the plateau surface. If the packet were a Noachian-age depositional unit, it would dip beneath the Hesperian units; it does not. If the packet were a Hesperian-age depositional unit, it should not be present under Noachian-age surfaces; it is present.

Similarly, a depositional origin for the layering cannot explain its continuity beneath and through the geological structures of impact craters. If the layering packet had been present before formation of the impact crater of Figure 1d, the packet would not be preserved beneath the crater. And if the layering packet had been deposited after formation of the crater, the packet would not be present beneath the topographic high of the crater rim. As neither prediction is fulfilled (Figure 1d), a depositional origin for the layering packet seems unlikely.

A diagenetic origin for the upper wall layering packet can explain its structure-transgressions, stratigraphic-transgression, and lateral extent. Diagenetic effects controlled by proximity to the ground surface would transgress preexisting features, including the boundary between Noachian and Hesperian deposits, and the structures and lithologic changes beneath and inside impact craters [Melosh, 1989]. Given similar compositions and permeabilities to fluids, diagenetic transformations should affect all earlier materials, regardless of their ages. And diagenetic layers can be of regional extent, like 
hardpans or calcretes on Earth (though none approach the areal extent described here). Diagenesis has been invoked to explain rock shapes at Viking lander sites and clodding of near-surface sediment [Fuller and Hargraves, 1978; Jakosky and Christensen, 1986], but again neither for such an extent and thickness as required by the upper wall layers in Valles Marineris.

\section{Implications}

A diagenetic origin for the upper wall layering packet has significant implications for climatic and geologic history of Mars. First, the diagenetic event must have happened relatively late in Martian history, upper Hesperian time at oldest, because it affected upper Hesperian materials of the upper member of the Syria Planum formation [Witbeck et al., 1991]. The absolute age of the upper Hesperian is probably $1.8 \mathrm{Ga}$ or younger [Tanaka et al., 1992; Treiman, 1995a]. The layering must be older than the formation of Valles Marineris itself, or at least its present wall exposures.

Second, formation of these diagenetic layers would seem to suggest the activity of aqueous solutions. Significant chemical transport would seem to be required to produce the observed variations in material strength (formation or removal of mineral cements) and in color (redistribution, formation, or removal of pigmentary phases). This degree of chemical transport seems unlikely by vapor alone (except for color changes by oxidation/reduction) or within solid ice.

Third, the formation of the layer packet was controlled by the present ground surface, as the packet is always at or very near the wall tops, independent of their elevation or geological unit. The packet could not have formed at a fixed groundwater table, because it would have approximated a gravitational equipotential surface [Clifford, 1993], and the plateau surface is not such a surface (Figure 3 ). Thus aqueous solutions must have been available near the ground surface and uniformly active over a vast area. Water for the diagenetic solutions could have been supplied by transient ground water, the melting of ground ice, or by precipitation.

And finally, the inference of liquid water near the ground surface, however rare or saline [Lucchitta, 1987], suggests a significantly different climate than at the present because aqueous solutions are not stable now near the Valles Marineris [Zent and Fanale, 1986; Clifford, 1993]. For aqueous brines to have been stable in the near subsurface (i.e., $<50 \mathrm{~m}$ depth), the temperature must have been above $\sim 250 \mathrm{~K}$ (the freezing temperature for $\mathrm{NaCl}$-saturated water [Clifford, 1993]) and the partial pressure of water vapor within pore spaces of the upper crust must have been at least $\sim 1$ mbar (the water vapor pressure over NaCl-saturated water at $250 \mathrm{~K}$ [Weast, 1985]) for portions of the Martian year. If pure water were to be stable, the temperature would have to be at least $273 \mathrm{~K}$ and the water vapor pressure at least 6 mbar [Weast, 1985].

These temperature limits for water stability may be marginally consistent with current conditions; maximum surface temperatures near the equator range up to $\sim 300 \mathrm{~K}$ [Carr et al., 1984], but temperatures below the diurnal layer are much colder: $-218 \mathrm{~K}$ average near the surface and possibly rising to $-260 \mathrm{~K}$ at $1-\mathrm{km}$ depth if heat flow is high [Clifford and Hillel, 1983; Clifford, 1993]. Thus a diagenetic origin for the wall layers suggests a warmer subsurface than at present.

Similarly, the current atmosphere is too dry to support aqueous solutions, with less than $2 \times 10^{-3}$ mbars of water vapor
( $<40$ precipitable $\mu$ meters [Jakosky and Haberle, 1992]). So, the pore spaces of the uppermost crust must have seen a much more humid atmosphere than is presently available. Such a high intergranular humidity would be possible if pore spaces of the upper crust were isolated from, hermetically sealed from, the current Martian atmosphere. But it seems unlikely (although not totally impossible) that the ground surface of Mars could be sealed over the whole region of the Valles Marineris. Thus high humidity in the uppermost crust would seem to imply a high humidity in Mars' atmosphere.

The stability of aqueous solutions on Mars must be considered in the context of the whole atmosphere. Most models of Mars' atmosphere and climate evolution require $\mathrm{CO}_{2}$ pressures greater than about a bar to permit liquid water on Mars' surface [see review in Fanale et al., 1992; Haberle et al., 1994; Squyres and Kasting, 1994]. If these models are credible and if our diagenesis hypothesis is correct, Mars should have had such an atmosphere when the diagenetic layer packet formed. Because the age of the layering packet is no older than upper Hesperian, probably $1.8 \mathrm{Ga}$ or younger [Tanaka et al., 1992; Treiman, 1995a], one may infer that Mars had a dense atmosphere at some time in the last $1.8 \mathrm{Ga}$, a far cry from the current -6 mbar $\mathrm{CO}_{2}$ and -0.002 mbars $\mathrm{H}_{2} \mathrm{O}$.

Such a drastic change in the Martian atmosphere is apparently beyond what could have been forced by a change in the obliquity of Mars' rotation axis. Mars' obliquity is calculated to vary chaotically from $0^{\circ}$ to near $60^{\circ}$ [Touma and Wisdom, 1993; Lascar and Robutel, 1993]; its current value is $25^{\circ}$. At high obliquities, several hundred mbars (or more) of $\mathrm{CO}_{2}$ could be injected into the atmosphere from sublimation of polar deposits of $\mathrm{CO}_{2}$ ice or water ice- $\mathrm{CO}_{2}$ clathrates [Jakosky et al., 1995]. However, this mass of $\mathrm{CO}_{2}$, in the absence of other factors, would appear inadequate to permit liquid water to be stable near Mars' surface.

The duration of this episode of dense atmosphere is unconstrained, as we know essentially nothing of the diagenetic processes and products involved in forming the upper wall layer packet. The Martian meteorites present some possible styles and products of aqueous alteration on Mars: Ca-carbonate-sulfate rich in the shergottites [Gooding, 1992]; clay-rich in the nakhlites [Treiman et al., 1993]; and Ca-Mg-Fe-carbonate-rich in ALH84001 [Mittlefehldt, 1994; Treiman, 1995b]. But the Martian sources for these meteorites are unknown, and their aqueous alteration materials may be unrelated to the hardpan. Given these uncertainties, it is premature to speculate on the mass of volatile compounds that might be sequestered in the upper wall hardpan layers.

\section{Conclusions}

The layering packet in the upper walls of Valles Marineris has implications far beyond its minor topographic and albedo expressions. Its lateral extent, greater than that of the Valles Marineris, suggests that it records events of global scale and significance. The stratigraphic position of the layer packet relative to known depositional and impact units imply that it formed in place, and the most probable mechanism for formation involves the action of liquid water solutions. Aqueous solutions are not stable now in the near-subsurface at Valles Marineris, and could only be stable under an atmosphere of approximately one or more bars $\mathrm{CO}_{2}$. The layering packet is of upper Hesperian age or younger, so this inferred dense atmosphere 
would have been present within the last $\sim 2 \mathrm{Ga}$, and would have been subsequently removed to leave the current thin atmosphere. The cause of this massive atmosphere so late in Mars' history is not constrained by our observations; obliquity variations, however, appear incapable of producing such drastic climate changes.

A critical unknown is the composition of the hardpan materials: the phases responsible for albedo differences within the layer packet, and responsible for the layering packet's relative resistance to erosion. The composition of the hardpan can be only poorly constrained with available data, but could be readily determined from: orbital multispectral imagery (visible, near-IR and thermal IR wavelengths) with spatial resolutions of tens of meters; in situ robotic investigations with similar multispectral imagery and/or chemical analysis instruments; or a returned sample.

Acknowledgments. This work was begun during an LPI Summer Internship to the second author. Advice and help from S. Clifford has been important through all phases of this work. We are grateful for access to the image collection in CIRS, and assistance from D. Reub, B. Fessler, R. Hurd, and S. Fuks. We appreciate careful and thorough reviews by $\mathrm{S}$. Clifford, F. Fanale, and an anonymous reviewer. Lunar and Planetary Institute contribution 874.

\section{References}

Carr, M.H., R.S. Saunders, R.G. Strom, D.E. Wilhelms, The geology of the terrestrial planets, NASA Spec. Publ. SP-469, 1984.

Clifford, S.M., A model for the hydrologic and climatic behavior of water on Mars, J. Geophys. Res., 98, 10,973-11,016, 1993.

Clifford, S.M., and D. Hillel, The stability of ground ice in the equatorial region of Mars, J. Geophys. Res., 88, 2456-2474, 1983.

Davis, P.A., and M.P. Golombek, Discontinuities in the shallow Martian crust at Lunae, Syria, and Sinai Plana, J. Geophys. Res., $95,14,231-14,248,1990$.

DeHon, R.A. Martian volcanic materials: Preliminary thickness estimates in the eastern Tharsis region, $J$. Geophys. Res., 87, 9821-9828, 1982.

DeHon, R.A., Ridged plains of Lunae Planum: Thickness distribution revised (abstract), Lunar Planet. Sci., XV/, 171-172, 1985.

DeHon, R.A., Progress in determining the thickness distribution of volcanic materials on Mars, in MEVTV Workshop on Nature and Composition of Surface Units on Mars, edited by J.R. Zimbelman, S.C. Solomon, and V.R. Sharpton. LPI Tech. Rep., 88-05, 54-56, 1988.

Fanale, F.P., Martian volatiles: Their degassing history and geochemical fate, Icarus, 28, 179-202, 1976.

Fanale, F.P., S.E. Postawko, J.B. Pollack, M.H. Carr, and R.O. Pepin, Mars: Epochal climate change and volatile history, in Mars, edited by H.H. Kieffer, B.M. Jakosky, C.W. Snyder and M.S. Matthews, pp. 1135-1179, Univ. of Ariz. Press, Tucson, 1992.

Fuller, A.O, and R.B. Hargraves, Some consequences of a liquid water saturated regolith in early Martian history, Icarus, 34, 614$621,1978$.

Geissler, P.E., R.B. Singer, and B.K. Lucchitta, Dark materials in Valles Marineris: Indications of the style of volcanism and magmatism on Mars, J. Geophys. Res., 95, 14,339-14,413, 1990.

Gooding, J.L., Soil mineralogy and chemistry on Mars: Possible clues from salts and clays in SNC meteorites, Icarus, 99, 28-41, 1992.

Haberle, R.M., D. Tyler, C.P. McKay, and W.L. Davis, A model for the evolution of $\mathrm{CO}_{2}$ on Mars, Icarus, 109, 102-120, 1994.

Jakosky, B.M., and P.R. Christensen, Global duricrust on Mars: Analysis of remote-sensing data, J. Geophys. Res., 91, 3547-3559, 1986.

Jakosky, B.M., and R.M. Haberle, The seasonal behavior of water on Mars, in Mars, edited by H.H. Kieffer, B.M. Jakosky, C.W. Snyder and M.S. Matthews, pp. 969-1016, Univ. of Ariz. Press, Tucson, 1992.
Jakosky, B.M., B.G. Henderson, and M.T. Mellon, Chaotic obliquity and the nature of the Martian climate, J. Geophys. Res., 100, 1579-1584, 1995.

Lascar, J., and P. Robutel, The chaotic obliquity of the planets, Nature, 361, 608-612, 1993.

Lucchitta, B.K., Morphology of chasma walls, U.S. Geol. Surv. J. Res. 6, 651-662, 1978.

Lucchitta, B.K., Valles Marineris, Mars: Wet debris flows and ground ice, Icarus 72, 411-429, 1987.

Lucchitta, B.K., A.S. McEwen, G.D. Clow, P.E. Geissler, R.B. Singer, R.A. Schulz, and S.W. Squyres, The Canyon system, in Mars, edited by H.H. Kieffer, B.M. Jakosky, C.W. Snyder and M.S. Matthews, pp. 453-492, Univ. of Ariz. Press, Tucson, 1992.

Melosh, H.J., Impact Cratering: A Geological Process, Oxford Univ. Press, New York, 1989.

Mittlefehldt, D.W., ALH84001, a cumulate orthopyroxenite member of the SNC meteorite group, Meteoritics, 29, 214-221, 1994.

Robinson, M.S., and K.L. Tanaka, Stratigraphy of the Kasei Valles region, Mars, in MEVTV Workshop on Nature and Composition of Surface Units on Mars, edited by J.R. Zimbelman, S.C. Solomon, and V.R. Sharpton. LPI Tech. Rep., 88-05, 106-108, 1988.

Soderblom, L.A., and D.B. Wenner, Possible fossil $\mathrm{H}_{2} \mathrm{O}$ liquid-ice interfaces in the Martian crust, Icarus, 34, 622-637, 1978.

Soderblom, L.A., The composition and mineralogy of the Martian surface from spectroscopic investigations: $0.3 \mu \mathrm{m}$ to $50 \mu \mathrm{m}$, in Mars, edited by H.H. Kieffer, B.M. Jakosky, C.W. Snyder and M.S. Matthews, pp. 557-593, Univ. of Ariz. Press, Tucson, 1992.

Squyres, S.W., and J.F. Kasting, Early Mars: How warm and how wet? Science, 265, 744-749, 1994.

Tanaka, K.L., D.H. Scott, and R. Greeley, Global Stratigraphy, in Mars, edited by H.H. Kieffer, B.M. Jakosky, C.W. Snyder and M.S. Matthews, pp. 345-382, Univ. of Ariz. Press, Tucson, 1992.

Touma, J., and J. Wisdom, The chaotic obliquity of Mars, Science, 259, 1294-1297, 1993.

Treiman, A.H., S $\neq$ NC: Multiple source areas for the Martian meteorites, J. Geophys. Res., 100, 5329-5340, 1995a.

Treiman, A.H., A petrographic history of Martian meteorite AlH84001: Two shocks and an ancient age, Meteoritics, 30, 294302, 1995b.

Treiman, A.H., R.L. Barrett, and J.L. Gooding, Preterrestrial alteration of the Lafayette (SNC) meteorite, Meteoritics, 28, 86-97, 1993.

U.S. Geological Survey, Topographic maps of the polar, western, and eastern regions of Mars, U.S. Geol. Surv. Map, I-2160, 1991.

U.S. Geological Survey, Mission to Mars: Digital topographic map, compact disks, Flagstaff, Ariz., 1993.

Weast, R.C., CRC Handbook of Chemistry and Physics, 66th ed., CRC Press, Boca Raton, Fla., 1985.

Witbeck, N.E., K.L. Tanaka, and D.H. Scott, Geologic map of the Valles Marineris region, Mars (east half and west half), U.S. Geol. Surv. Map, I-2010, 1991.

Zent, A., and F.P. Fanale, Possible Mars brines: Equilibrium and kinetic considerations. Proc. Lunar Planet. Sci. Conf. 16th, Part 2, J. Geophys Res., 91, suppl., D429-D445, 1986.

Kelly H. Fuks, Department of Geological Sciences, 1009 C.C. Little Bldg., University of Michigan, Ann Arbor MI 48109 (e-mail: kfuks@umich.edu)

Scott Murchie, Applied Physics Laboratory, Johns Hopkins University, Johns Hopkins Road, Laurel MD 20723 (e-mail: scott murchie@jhuapl.edu)

Allan H. Treiman, Lunar and Planetary Institute, 3600 Bay Area Boulevard, Houston TX 77058-1113 USA (e-mail: treiman @lpi.jsc.nasa.gov)

(Received July 19, 1995; revised October 12, 1995; accepted October 21, 1995.) 